\title{
BREAST CANCER SCREENING IN THE UK: EXPERIENCE TRANSFER TO BULGARIA
}

\author{
P. Petrova, A. Kerekovska, N. Feschieva \\ Department of Social Medicine and Health Care Organisation, Medical University Prof. Dr. \\ Paraskev Stoyanov, Varna
}

Reviewed by: Assoc. prof. R. Radev, PhD

\section{SUMMARY}

\begin{abstract}
Breast cancer is currently the most prevalent cancer and the most frequent cause of cancer-induced deaths in women in Europe. Demographic trends indicate a continuing increase in this substantial public health problem and Bulgaria does not differ from these negative trends. Evidence from many European countries shows that systematic early detection through screening, effective diagnostic pathways and optimal treatment have the ability to substantially lower current breast cancer mortality rates and reduce the burden of this disease in the population. The achievements of the UK as a "gold standard" country in breast cancer screening, diagnostics and treatment is indisputable and its experience - worthy of exploration. This study aims to comparatively analyze the breast cancer screening practices in the two countries and on that basis to draw out specific recommendations for experience transfer from the UK to Bulgaria. The methods involve comparative analysis of screening practices in the two countries and documentary analysis in the area of breast cancer prevention field. A major emphasis is placed on the NHS Breast Screening Programme. Its main advantages and positive experiences are summarized. The most important ones identified as suitable for transfer to Bulgaria refer to: economic preliminary assessments; effective management process; prioritisation of quality assurance activities; continuous updates of the programme based on research outcomes and evidence-based practice; systematic involvement of the primary health care teams; public and professional education, and political support. In the context of globalizing society and limited resources, experience transfer of the best practices is a rational approach for solving important public health problems.
\end{abstract}

Keywords: screening, breast cancer, transfer, United Kingdom, Bulgaria

\section{INTRODUCTION}

Breast cancer is the most common cancer in women worldwide. It accounts for over $26 \%$ of all female malignancies and represents the leading cause of death in $40-55$ years old women. Over one million new cases occur each year worldwide and about 410,000 women die out of the disease annually (11). Incidence has been rising in many parts of the world, including the USA, Canada, Europe, the Nordic countries, Singapore and Japan (8). Due to demographic trends, significantly more women will be confronted with this disease in the future. Despite the rising incidence, sustainable trends of decreasing mortality have been observed for the last years in the developed countries, which are related to the successfully implemented screening

\footnotetext{
Address for correspondence:

A. Kerekovska, Dept. of Social Medicine and Healthcare Organisation, Medical University Prof. Dr. Paraskev Stoyanov, 55 Marin Drinov St., BG-9002, Varna, BULGARI

E-mail: kerekovska_a@yahoo.com
}

programmes, early diagnosis, timely and effective treatment.

Indeed, solid evidences on the importance of the early diagnosis and effectiveness of population-based screening programmes have been accumulated $(6,9,11)$. Systematic screening of the female population based on mammography offers the perspective of saving many lives while reducing the negative side-effects of treatment by detecting cancer at earlier stages, when it is more responsive to less aggressive treatment. These benefits can only be achieved, however, if the quality of services offered to women is optimal. Administration and quality assurance of population-based breast screening programmes are therefore challenging endeavour encompassing the entire screening process (10).

Countries with high breast cancer prevalence have long experience in the development, implementation and administration of breast cancer screening programmes. In 1990, the "Europe against Cancer" programme was initiated to unite the efforts and experience of the European countries in the fight against the disease. In 1998, European Breast Cancer Network was established in which scientists, clinicians and paramedical staff as well as advocates, health care planners 
and administrators across Europe have shared experiences. In its efforts to decrease the breast cancer death rates in Europe, the European Commission published the fourth edition of the European Guidelines for Quality Assurance in Breast Cancer Screening and Diagnosis, setting out a balance of best practice and performance indicators which can be used across a wide spectrum of cultural and economic healthcare settings across Europe (10).

The UK national guidelines and its experience have formed some of the foundations of the European Breast Cancer Screening Guidelines. This country is greatly affected by the burden of breast cancer. Over 42,000 new cases occur each year and about 12,400 British women die out of the disease. Until 1999 breast cancer has been the leading cause of death among women in the UK $(6,8)$. However, its achievements in screening, diagnostics and treatment of breast cancer are indisputable. Earlier detection by screening since 1988 in the UK has had a marked impact, reducing mortality rates from breast cancer. Fairly constant or slightly increasing during the $1980 \mathrm{~s}$, breast cancer death rates in England and Wales have fallen in all age groups by about $25 \%$ since 1990 . This rapid decline in mortality is believed to be partly the result of earlier diagnosis of breast cancer, which is associated with screening and increasing breast awareness, and partly the result of increased use of hormonal and other effective therapies. Data reveals substantial survival improvements, also related to the effective screening and earlier detection of the disease. The estimated relative five-year survival rate for women diagnosed in England and Wales in 2001-2003 was 80\%, compared with only $52 \%$ for those diagnosed in 1971-1975 (6).

Breast cancer is an important public health problem for Bulgaria too. It is the most prevalent oncologic disease in Bulgarian women. Over 36,000 of them currently suffer from it, and the incidence of the disease is constantly increasing from 43.6 per 100,000 in 1981 it rises up to 74.4 per 100,000 in 2000 to reach the level of 83.2 per 100,000 women in 2005 (4). There are over 3,500 newly registered cases per year. Contrary to the decreasing mortality trends in the EU and North American countries, breast cancer death rates in Bulgaria are continuously increasing - from 19.6 per 100,000 women in 1981 to 27.2 per 100,000 in 2000 and still rising (4). A major problem for the country is the late detection of the disease, which is closely related to the ineffective screening practices. Compared to the developed countries, the share of the early-diagnosed pre-symptomatic cases is significantly lower in Bulgaria - only 14\% are detected in the $1^{\text {st }}$ stage of the disease. The proportion of the cases diagnosed in the advanced $\left(3^{\text {rd }}\right.$ and $\left.4^{\text {th }}\right)$ stage of the disease is over $40 \%(4,5)$.

The British experience, as one of the first countries having introduced national screening programmes and achieving substantial progress in effective screening practices, is a good basis to be explored. Transfer of positive experience could be of great value for screening programmes development and implementation, patients' and professionals' education and recommendations for raising public awareness and action in the fight against the disease. An adequate transfer of the UK best practice to the Bulgarian context could substantially contribute to the successful implementation of the national strategy and working programmes on preventive oncological screening.

This study aims to comparatively analyze the breast cancer screening practices in the two countries and on that basis to draw out specific recommendations for experience transfer from the UK to Bulgaria.

\section{MATERIALS AND METHODS}

The methods involve comparative analysis of screening practices in the UK and Bulgaria and documentary analysis in the area of breast cancer prevention field. A major emphasis is placed on the National Health Service Breast Screening Programme (NHSBSP). The study summarizes the UK's main advantages and positive experiences and identifies those practices that are suitable for transfer to Bulgaria. It also draws out concrete recommendations for their adaptation to the Bulgarian national context.

\section{RESULTS AND DISCUSSION}

The NHS Breast Screening Programme (NHSBSP) began in 1988. Its current organisation is based on the advice of the Forrest Report, which was published in 1986 in the context of the NHS structure in place during the late 1980s. Further guidance on the organisation of breast screening programmes, and in particular on its assessment, was set out in Organising Assessment, which was published by the NHSBSP in 1989. Since then, there have been changes to the role and size of health authorities along with the introduction of NHS trusts and commissioning by primary care trusts (PCTs). Further organisational changes announced in Shifting the Balance of Power within the NHS along with the extension of the age range for invitation for screening to women aged up to and including 70 , showed that revised guidance on the organisation of local screening programmes is needed in order that local commissioning and cancer networks can have a service that best reflects the needs of the local population and general patient flows (7).

The NHSBSP development goes through three phases: the first - involving the establishment of the screening centers, personnel recruitment and education, and standards development for the assessment of the entire process; the second - focusing on summarizing the outcome of the initial phase; and the third - involving revision of the initially developed standards and reporting results of programme's implementation (7). Breast cancer screening in the UK takes place in 80 screening centers including also mobile teams. Initially, the NHSBSP employed single view mammography and invited women aged 50-64 years for screening once every three years. By 2005, the programme was using two view mammography and screening 1.3 million women aged $50-70$ years annually, about $75 \%$ of those invited. Currently, it diagnoses about 10,000 breast cancers 
annually. Breast cancer registrations at ages 50-64 years have increased by almost $50 \%$ since 1988 . It is estimated that about half of this increase is due to screening and about half is due to an increase in the underlying incidence of breast cancer (6).

Good quality of the management process is of primary importance for the successful functioning of the screening programme. This refers to the call and recall system management; planning the screening round; liaison with other organisations such as cancer networks, strategic health authorities, PCTs, cancer registries; managing the budget; managing staff; staff development; site management; maintenance of equipment and facilities; responsibility for the quality management system; collecting performance data [6]. Each Regional Health Authority is responsible for the screening provision and management of the screening centers. This necessitates very good co-ordination between the regional health authorities, FPCs, GPs and the oncologists. Quality assurance is an underpinning principle of the NHSBSP. Overall standards for the programme are set and quality assurance manager and reference centre are established in each region [6]. The role of the outpatient care sector and especially the primary health care team is recognized as vitally important for the successful realization of the screening process. Special training is provided for all professionals involved in the programme including the PHC team to raise their awareness and knowledge and to also increase and sustain their positive attitude for taking part in the prevention activities and the regional screening programmes [5].

Research and evidence based practice are essential part of the screening process, as they ensure opportunities for its improvement, cost-effectiveness and optimization. The NHSBSP has always considered research as central to its goal to provide a service based as much as possible on the best available evidence. For the purpose, research and development management group has been established - the Breast Cancer Screening Research Sub-Committee and an extensive body of research has been carried out. Three randomised trials were started at the beginning of the programme looking specifically at screening questions: the age trial, the frequency trial and the one view versus two views trial (6). The data confirmed that two-view mammography is more effective than the single-view and that annual screening does not bring better results than the once-in-three-years systematic screening. Research results also proved that 40-49 age group screening is effective, but rather inefficient because of the high cost/utility ratio. The NHS screening programme regularly works with academic institutions to investigate various aspects of breast screening, mammography and the causes and treatment of early breast cancer. This has yielded data about the effects of changes in the programme and also about its operation, such as the effect of size of unit on performance. The last recommendations, for instance, for the NHSBSP future work are based on systematic review and evidence analysis incorporating meta-analysis, randomized clinical trials, descriptive and analytical epidemiological studies, case stud- ies and also clinical expertise of various health committees (6). Such data also is essential for the programme's planning, outcomes evaluation and financial assessment. Systematic research activities will continue as long as the screening programme operates in order to refine the programme, to take advantage of new knowledge and techniques and to improve the treatment of women with screen detected disease (6).

In Bulgaria, the oncological diseases, and especially breast cancer, are considered a major priority of the national health policy. One of the main goals of the National Health Strategy (1) is to enhance the effectiveness of their prevention and treatment. In this connection, National Strategy for the 2001-2006 period and Working Programme for Preventive Cancer Screening and Risk Groups Detection (2) were developed in Bulgaria, and a new 2007-2012 strategy is being currently discussed. They aim to increase the proportion of the early detected and effectively treated cases and to substantially decrease (by $30 \%$ ) cancer mortality rates.

Different health professionals are involved in the prevention, early detection, treatment and rehabilitation of breast cancer in Bulgaria. The PHC package of the GPs, for instance, includes clinical breast examination of women aged 31-69 on an annual basis and risk assessment. All women included in the risk groups should receive a preventive check-up exam (including mammography) once a year by a specialist (breast surgeon) according to the National Framework Contract (3) (signed out annually between the Bulgarian Medical Association and the National Health Insurance Fund (NHIF)). These activities are financed by the NHIF and carried out according to the Ministry of Health Ordinance for preventive check-ups and dispensarisation and the Ordinance for main package of health activities guaranteed by NHIF budget. Once diagnosed, the complete treatment and care of the oncological patients are carried out by the Regional Dispensaries for Oncological Diseases - specialised units organized on a regional principle.

Special Programme on cervical and breast cancer prevention and control has been developed and is coordinated by the National Centre for Active Oncological Treatment and the Bulgarian National Oncology Association. The general practitioner is a main figure involved in the process of breast cancer early detection and diagnostics. The GPs should regularly report to the NHIF on the activities performed within the Programme, however they are not sufficiently active and engaged with the screening and preventive practices. Some studies relate the problem to the GPs' low motivation, insufficient knowledge and self-confidence for screening participation as well as to the lack of awareness and positive attitudes of great part of the women for taking part in the screening examinations. The situation analysis of the breast screening practices in Bulgaria reveals insufficient activity and low screening effectiveness, as well as problems with the management and quality assurance of the programme's administration (5). There have been some local initiatives throughout the country that have achieved good initial results. However, the activities have 
been sporadic, campaign oriented and disunited, and the services proved to be not accessible for the women from small and isolated areas. The effective realization of the national population-based breast-screening programme remains a major problem to be solved in the country (5). NHSBCP positive experience and practices that are suitable for transfer to Bulgaria are drawn out; however, they need to be adapted to the country's specific context. For successful transfer from the UK to Bulgaria, it is necessary to consider the differences in socio-economic development, existing institutional structure and cultural distinctions of the two countries. The British breast cancer screening practices identified as suitable for transfer to Bulgaria can be summarized to (5):

- Detailed preliminary (before programme's initiation) and ongoing economic assessment and precise financial planning to assure adequate coverage of the increased needs of all regional (diagnostic and treatment) health units;

- Establishment of Quality Assurance System within the breast cancer screening programme; All units carrying out screening, diagnosis or assessment must work to agreed protocols forming part of a local quality assurance manual, based on national or European documents containing accepted clinical standards and published values. They should work within a specialist framework, adhering to set performance indicators and targets; Introduction of a robust and reliable system of accreditation for the screening units to ensure operation to a satisfactory standard;

- Maintaining high quality of the programme's management process and perfect co-ordination between the all structures and bodies involved in the programme implementation (screening units, GPs' practices, registries, etc.). Assurance of complete co-operation between the screening programme and the National Cancer Register as well as between the regional and district health authorities; Clear determination and distribution of responsibilities between everyone involved in the screening process and working in the screening teams;

- Call and recall system improvements for achieving maximum screening coverage; Special attention paid to the groups of women with specific problems, such as disabled, mentally retarded, ethnic minorities; Assuring better access to services for women from small and isolated localities;

- Establishment of integrated electronic information system for calling and recalling, diagnostic confirmation and follow-up of detected abnormalities; Complete and accurate recording of all individual data concerning the target population, the screening test, its result, decisions made and the eventual outcome in terms of diagnosis and treatment;

- Adequate programme monitoring, supervision, feed-back and update;

- Engaging sufficiently skilled and specifically trained personnel; All staff in the screening programme should hold professional qualifications, undertake specialist training, participate in continuing medical education and updates, take part in any recognised external quality assessment schemes, hold any necessary certificate of competence;

- Informing the patients in an appropriate and unbiased manner in order to allow fully informed decision as to whether to attend. Information provided must be balanced, honest, adequate, truthful, evidence-based, accessible, respectful and tailored to individual needs where possible;

- Systematic involvement and active participation of the outpatient sector and especially the PHC team and the GPs in the programme's promotion and preparation of lists of women eligible for screening; Raising public awareness and knowledge and establishing positive attitudes for taking part in the screening process - not only during the campaigns, but systematically through the every-day practice of the GPs and other medical professionals;

- Research and evidence based practice should be constant components of the screening programme, essential for the service improvement and costs optimization. Therefore, screening practice should be accompanied by prospective scientific studies for programme's health impact assessment and economic evaluation.

- Government support should be ensured in order to achieve high quality screening, diagnostic and breast care services. Establishment of a meaningful quality-assured programme rely on sufficient infrastructure, financing and supervision, all of which require political goodwill to implement and maintain.

\section{CONCLUSION}

Breast cancer is currently the most prevalent cancer and the most frequent cause of cancer-induced deaths in women in Europe. Demographic trends indicate a continuing increase in this substantial public health problem (8). Evidence from many European countries shows that systematic early detection through screening, effective diagnostic pathways and optimal treatment have the ability to substantially lower current breast cancer mortality rates and reduce the burden of this disease in the population (10).

The experience of the UK, being one of the first countries introducing breast screening programme on a national level and achieving good results from its effective implementation, is a good basis to be explored. Looking for positive experience suitable for transfer to the Bulgarian context could be of great value for the optimization of the country's screening practices development and administration. An adequate transfer of the UK best practice to the Bulgarian context would necessitate due consideration of the different socio-economic development, existing institutional structures and cultural peculiarities of the two countries. The most important breast-screening practices of the UK identi- 
fied as suitable for transfer to Bulgaria generally refer to: economic preliminary assessments; effective management process; prioritisation of quality assurance activities; continuous updates of the programme based on research outcomes and evidence-based practice; systematic involvement of the primary health care teams; public and professional education, and ensuring government support. In the context of globalizing society and limited resources, experience transfer of the best practices is a rational approach for solving important public health problems.

\section{REFERENCES}

1. Министерство на здравеопазването. Национална здравна стратегия "По-добро здраве за по-добро бъдеще на България”, С., 2001.

2. Министерство на здравеопазването. Национална стратегия и работна програма за превантивен онкологичен скрининг в Република България (2001-2006). (<http://www.mh.government.bg/ program_and_strategies.php $>$ ).

3. Министерство на здравеопазването. Национален рамков договор (2006) (http://84.252.8.147/DKC_V/NRD\%202006.htm).

4. Национален центьр по здравна информация. Министерство на здравеопазването. Регистрирани злокачествени заболявания - 2005. НЦЗИ (http://www.nchi.government.bg/statistika/B_3.pdf).
5. Петрова, П. Политика за превенция на рака на млечната жлеза във Великобритания и България сравнително проучване. Магистьрски тезис,

Магистьрска програма „Обществено здравеопазване”, Медицински университет Варна, 2006.

6. Advisory Committee on Breast Cancer Screening. Screening for Breast Cancer in England: Past and Future. NHS Cancer Screening Programmes 2006.

NHSBSP Publication No 61, February 2006. (http://www.cancerscreening.nhs.uk/breastscreen/brea stcancer.html)

7. Briggs, P., S. Gray, J. Patnick, R. Blanks. Organising a Breast Screening Programme. NHS Cancer Screening Programmes 2002. NHSBSP Publication No 52, December 2002. (http://www.cancer screening.nhs.uk/breastscreen/breastcancer.html).

8. Cancer Research UK. UK Breast Cancer statistics, 2006. (http://info.cancerresearchuk. org:8000/cancerstats/types/breast).

9. Fentiman, I. Detection and treatment of breast cancer. $2^{\text {nd }}$ ed. London, Martin Dienitz Ltd; 1998, pp. 95-107.

10. Perry, N., M. Broeders, C. de Wolf, R. Holland, L. von Karsa. European Guidelines for Quality Assurance in Breast Cancer Screening and Diagnosis, $4^{\text {th }}$ ed., 2006 (http://europa.eu.int/ comm/dgs/health_consumer/index_en.htm).

11. Spratt, J., W. Donegan. Cancer of the Breast. Elsevier Science-Saunders (USA), 2002, pp 111-133. 